\title{
Damping of Fe-Al Alloy Electrodeposited in an Ionic Liquid
}

\author{
Osvaldo Agustin Lambri * ${ }^{\star D}$, Bernd Weidenfeller ${ }^{b}$, Federico Guillermo Bonifacich ${ }^{a}$,
}

Giridar Pulletikurthic, Jiayi Xuc ${ }^{c}$,Laura Weidenfeller ${ }^{d}$, Frank Endres

\author{
${ }^{a}$ Consejo Nacional de Investigaciones Cientificas y Técnicas, Universidade Nacional de Rosario - \\ CONICET-UNR, Laboratorio de Materiales, Escuela de Ingeniería Eléctrica, Facultad de Ciencias \\ Exactas, Ingeniería y Agrimensura, 2000 Rosario, Santa Fe, Argentina. \\ ${ }^{b}$ Department of Materials Science - IEC, Clausthal University of Technology, D-38678, Clausthal- \\ Zellerfeld, Germany \\ 'Institute of Electrochemistry, Clausthal University of Technology, D-38678 Clausthal-Zellerfeld, \\ Germany \\ ${ }^{d}$ Institute of Physics, University of Kassel, D-34132 Kassel, Germany
}

Received: September 05, 2017; Revised: May 18, 2018; Accepted: August 29, 2018

\begin{abstract}
Iron-Aluminium alloys were produced by the electro-deposition of iron-aluminium on a copper substrate. The electro-deposition process was done in the ionic liquid 1-butyl-1-methylpyrrolidinium trifluoromethylsulfonate, $\left[\mathrm{Py}_{1,4}\right] \mathrm{TfO}$. A solution of $\left(0.2 \mathrm{M} \mathrm{FeCl}_{2}+2.75 \mathrm{M} \mathrm{AlCl}_{3}\right) /\left[\mathrm{Py}_{1,4}\right] \mathrm{TfO}$ was used at a temperature of $\mathrm{T}=363 \mathrm{~K}$ because this mixture is solid at room temperature. Electrodeposited samples were studied by means of mechanical spectroscopy, differential thermal analysis and laser light microscopy. Mechanical spectroscopy studies were performed as a function of temperature, frequency and strain. The usual damping peaks for copper, low temperature grain boundary peak, recovery peak and intermediate temperature grain boundary peak were observed. In addition, a new damping peak at around $800 \mathrm{~K}$ which is not thermally activated was discovered. The physical mechanism controlling the appearance of this new peak is the dissolution of small precipitates or agglomerates of defects which take place at around $800 \mathrm{~K}$ during the warming and the subsequent re-precipitation/re-agglomeration during the cooling. This process could occur either in the copper substrate or at the Fe-Al electrodeposit.
\end{abstract}

Keywords: Fe-Al alloy, electrodeposited alloys, precipitation processes, mechanical spectroscopy.

\section{Introduction}

Soft magnetic materials are involved in technological devices for conversion of energy such as electrical power generators, transformers and electric motors. Iron, nickel, cobalt and their alloys are used in several technological devices. The addition of silicon to iron improves its magnetic properties by increasing the resistivity and magnetic permeability and reducing the coercive field, energy losses and magnetostriction. However, silicon has a deleterious effect on the ductility of iron. For instance, Fe-6.5 wt.\% $\mathrm{Si}$ alloys have soft magnetic properties and extremely low magnetostriction values, that enables them to be used as core elements in transformers and flux amplifier systems ${ }^{1-3}$. In Fe-based alloys, the ordering and the interaction processes among substitutional atoms, structural defects and grain boundaries have a great importance on the magnetic quality. In addition, iron-silicon-aluminium alloys exhibit a lowelectrical resistivity near the compositions $\mathrm{Fe}_{3} \mathrm{Si}$ and $\mathrm{Fe}_{3} \mathrm{Al}$ and in ternary alloys lying between them. This low resistivity must be connected with the ordered atomic arrangement well known to exist in the binary systems and also reported to

*e-mail: olambri@fceia.unr.edu.ar occur in ternary alloys ${ }^{4}$. Moreover, the addition of around $12 \mathrm{wt} \%$ aluminium leads to zero crystal anisotropy, and therefore Fe-Si-Al alloys with high contents of silicon and aluminium exhibit very low coercive forces and very high permeability values. However, these alloys are very brittle and cannot be produced by cold rolling. Melt spinning leads only to very thin strips and often to high dislocation densities. The dislocation density can be minimized by heat treatment and nanocrystals can be formed in the strips ${ }^{5}$.

A new method to produce such nanocrystalline Fe-Al, Fe$\mathrm{Si}$ and $\mathrm{Fe}-\mathrm{Si}$-Al alloys is the co-deposition of these elements by means of electro-deposition processes. A deposition of single domain crystals is interesting due to expected nearly zero magnetization reversal power losses. Furthermore, by changing the deposition voltage the composition of the deposit can be varied ${ }^{5}$.

Mechanical spectroscopy (measurements of damping and elastic modulus as a function of temperature), also called internal friction method in the early literature, is an experimental technique very sensitive to the microstuctural state and to the interaction processes among defects ${ }^{6}$. Therefore, the aim of the present work is to study the mechanical behaviour by means of mechanical spectroscopy of $\mathrm{Cu}-\mathrm{Fe}-\mathrm{Al}$ samples made from the iron-aluminium electrodeposition on a copper 
substrate. A new damping peak at around $800 \mathrm{~K}$ appears in electrodeposited samples both on warming and cooling runs, which cannot be related to the usual relaxation peaks from copper. Mechanical spectroscopy studies were performed also as a function of frequency and strain. The amplitude dependent damping results gave important information about the dislocation dynamics in this $\mathrm{Cu}-\mathrm{Fe}-\mathrm{Al}$ alloy. In addition, differential thermal analysis and laser light microscopy studies were also carried out.

\section{Experimental}

\subsection{Materials}

For the electro-deposition of $\mathrm{Fe}$ and its alloys with $\mathrm{Al}$ from 1-butyl-1-methylpyrrolidinium trifluoromethylsulfonate, $\left(\mathrm{Py}_{1,4}\right) \mathrm{TfO}$, with a purity of $99 \%$, was purchased from IOLITEC GmbH, Germany. The water content of the asreceived $\left(\mathrm{Py}_{1,4}\right) \mathrm{TfO}$ was measured to be $341 \mathrm{ppm}$ by using Karl-Fischer titration. Furthermore, the liquid contained trifluoromethylsulfonic acid in the $100 \mathrm{ppm}$ regime. The $\left(\mathrm{Py}_{1,4}\right) \mathrm{TfO}$ was dried for 2 days at $373 \mathrm{~K}$ under vacuum to a water content of $5 \mathrm{ppm}$ and stored in a closed bottle in an argon-filled glove box (OMNI-LAB from Vacuum Atmospheres) with water and oxygen contents below 2 ppm.

Iron(II) chloride $\left(\mathrm{FeCl}_{2}\right)$ for the electro-deposition of $\mathrm{Fe}$ from $\left(\mathrm{Py}_{1,4}\right)$ TfO was used. $\mathrm{FeCl}_{2}(>99.5 \%)$ was purchased from ALFA, Germany. For the preparation of FeAl alloys aluminium chloride grains $(>99 \%$ ) were purchased from FLUKA, Germany.

\subsection{Electro-deposition}

Iron-aluminium alloys were electrodeposited from the ionic liquid 1-butyl-1-methylpyrrolidinium trifluoromethylsulfonate, $\left(\mathrm{Py}_{1,4}\right) \mathrm{TfO}$ on a copper substrate. A solution of $\left(0.2 \mathrm{M} \mathrm{FeCl}_{2}+\right.$ $\left.2.75 \mathrm{M} \mathrm{AlCl}_{3}\right) /\left(\mathrm{Py}_{1,4}\right) \mathrm{TfO}$ was used at a temperature of $\mathrm{T}=363$ $\mathrm{K}$ because this mixture is a solid at room temperature. $\mathrm{Pt}$ wires were used as quasireference and counter electrodes, respectively. For Al electro-deposition studies, Al wires were used as reference and counter electrodes, respectively; and copper was used as a working electrode. For electrodeposition studies of Fe and FeAl alloys, a Pt wire was used as a reference electrode. An Al wire was used as a counter electrode for iron-aluminium deposition experiments.

The onset of iron deposition was found to occur at a potential of $-0.52 \mathrm{~V}$, the onset of iron-aluminium codeposition was found to be around $-0.95 \mathrm{~V}$ and the onset of bulk aluminium deposition was found to be at $-1.9 \mathrm{~V}$. At the chosen deposition potential of $-1.1 \mathrm{~V}$, a Fe $2.5 \mathrm{wt} \% \mathrm{Al}$ alloy of approximately $10 \mu \mathrm{m}$ thickness was deposited after 2 hours. Grain sizes estimated by SEM, XRD and magnetic measurements were lying at $50-75 \mathrm{~nm}$. A more detailed description of these characterization methods and results is given in Ref. 5 . Due to the moisture sensitivity of the ionic liquid and the affinity to corrosion of the deposit, the preparation was done in a glove box under Ar atmosphere.

\subsection{Measurements}

Mechanical spectroscopy (MS) studies were performed in an inverted torsion pendulum under high vacuum at $10^{-5}$ $\mathrm{Pa}$. The maximum strain on the sample surface was $5 \times 10^{-5}$. The measurement frequency was around $1 \mathrm{~Hz}$, except for measurements performed to obtain the activation energy of the relaxation processes.

MS measurements were performed following subsequent heating and cooling runs on each sample. A heating run and its following cooling run is called a thermal cycle. Different final temperatures for the cycles were used.

The damping value, $\mathrm{Q}^{-1}$, was calculated from the slope of the natural logarithm of the decaying amplitudes versus the period number, such that

$$
\ln \left(A_{n}\right)=\ln \left(A_{0}\right)-\pi Q^{-1} n
$$

where $A_{n}$ is the area of the $n^{\text {th }}$ decaying oscillation, $A_{0}$ is the initial area of the starting decaying oscillation and $n$ is the period number. For all these measurements the same initial and final values of the decaying amplitudes were used to avoid distortions linked to the appearance of amplitude dependent damping (ADD) effects ${ }^{7,8}$. The decaying of the oscillations was performed at constant temperature $\left(T \pm 0.5^{\circ}\right)$.

The ADD effects, i.e. the damping as a function of the maximum strain on the sample, $\varepsilon_{0}$, was calculated from the following equation in the different n-ranges (or $\varepsilon_{o}$-ranges) of the decaying cycle ${ }^{7,9}$ :

$$
Q^{-1}\left(\varepsilon_{0}\right)=-\frac{1}{\pi} \frac{d\left(\ln \left(A_{n}\right)\right)}{d n}
$$

This procedure allows to obtain the damping as a function of the maximum strain $\left(\varepsilon_{0}\right)$ from free decaying oscillations ${ }^{7,9}$. Polynomials with degree above 1 indicate that $\mathrm{Q}^{-1}$ is a function of $\varepsilon_{0}$, leading to the appearance of ADD effects.

The strength of ADD effects is measured through $\mathrm{S}$ parameter, such that ${ }^{10}$

$$
S=\frac{\Delta Q^{-1}}{\Delta \varepsilon_{0}}
$$

being $\Delta \mathrm{Q}^{-1}$ the damping change measured when the amplitude changes $\Delta \varepsilon_{0}$.

Differential thermal analysis (DTA) measurements were performed in a conventional calorimetric equipment employing stainless steel crucibles under argon at atmospheric pressure. The heating rate, controlled by a Lake Shore controller, was $5 \mathrm{~K} /$ minute, starting from room temperature up to $1023 \mathrm{~K}$.

A light microscopy using a flush green laser source was performed at an Arcano metallographic microscope with digital camera at room temperature. The lightning was performed with monochromatic and coherent light (laser light) due to 
that an improvement for revealing morphologies of irregular surfaces can be reached by means of such technique ${ }^{11}$.

\section{Results and Discussion}

Figure 1.a shows the damping spectra measured during warming for non-electrodeposited and electrodeposited samples during several thermal cycles up to different temperatures. Each damping spectrum plotted in all figures throughout this work shows for reasons of clarity only every seventh measurement point. For the copper substrate, the spectrum exhibits the well known low temperature grain boundary damping peak (LTP, also called solvent grain boundary damping peak) at around $520 \mathrm{~K}$, the peak related to the recovery of the structure at around $650 \mathrm{~K}(\mathrm{RP})$ and the intermediate temperature grain boundary damping peak (ITP) at around $700 \mathrm{~K}$. The RP and ITP appear overlapped on the high temperature tail of LTP, see full circles ${ }^{6,12-15}$.
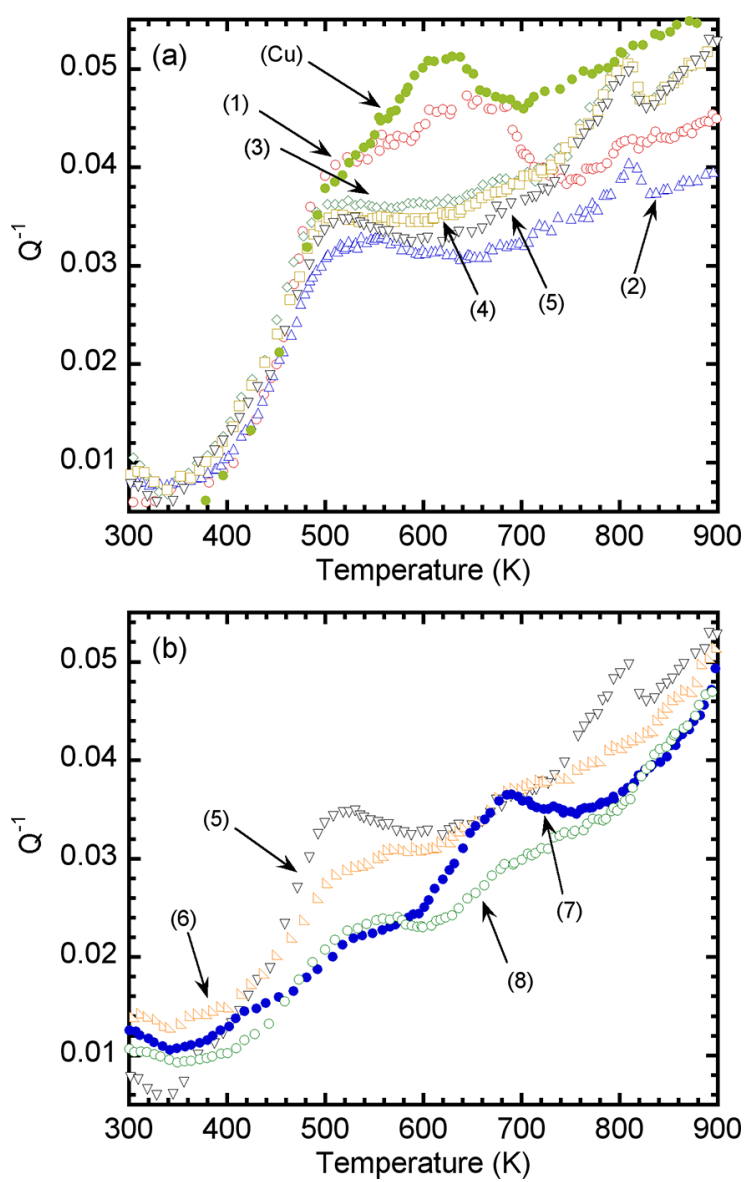

Figure 1. Damping spectra measured during warming for the copper substrate and for the electrodeposited samples. Curves \# 1 to \#8, thermal cycles for electrodeposited sample. (a) Curves \#1 to \#4: cycles up to $973 \mathrm{~K}$. Curve \# 5: Thermal cycle up to $1173 \mathrm{~K}$. (b) Curve \# 6: Heating run after an annealing up to $1173 \mathrm{~K}$. Curve \# 7: First heating run after "in situ" plastic deformation $(1.5 \%$ torsion at room temperature). Curve \#8: Second warming after plastic deformation.
The electrodeposited sample, during the first warming (empty circles), shows the appearance of the LTP, RP and ITP with similar characteristics than for the copper substrate. It indicates that the electro-deposition process does not affect markedly the grain boundary mobility for the sample in the as-electrodeposited state. The RP appears almost similar in the electrodeposited samples due to the used electro-deposition temperature, which is clearly below the recovery temperature for copper. Nevertheless, at higher temperatures than the ITP, a small peak at around $800 \mathrm{~K}$ can be observed, which will be called hereafter the new peak (NP). Moreover, during successive thermal cycles up to $973 \mathrm{~K}$, the peak height of NP increases. In contrast, after the first thermal cycle the peak height of the LTP and RP have decreased.

In the cooling run of the first thermal cycle the peak height of the LTP is decreased and the height of the NP is increased. In the heating run of the second and later cycles the height of the LTP shows no significant changes. The cooling and heating runs of the damping spectra after the first thermal cycle are showing a similar behaviour. However, the peak height for NP increases as the number of cycles increases. For the sake of clarity, cooling curves were not shown in the Figure.

The decrease in the height of LTP could be controlled by the amount of solute atoms in the copper due to the dissolution of some precipitates or agglomerates of defects caused by the annealing during the first heating run up to the maximum temperature. In fact, the precipitation or dissolution of precipitates lead to an increase and decrease in the height of the grain boundary solvent peak, respectively, due to the changes of the grain boundary sliding capability ${ }^{6,16,17}$. The adding of solute atoms in alloys gives rise both to the decrease in the LTP height and to the appearance of a new peak at higher temperatures, called the solute grain boundary peak $^{12,14,16-18}$.

After a heating run up to $1173 \mathrm{~K}$, the NP strongly decreases and also the peak height of LTP decreases again, see squared triangles in Figure 1.b. Besides, the effect of an "in situ" plastic torsion deformation at the spectrometer of $1.5 \%$ at room temperature was also studied. The spectrum for the deformed sample measured during warming up to $973 \mathrm{~K}$, full circles in Figure 1.b, exhibits a decrease both in the background values near to room temperature and in the peak height of LTP. In addition, the re-appearance of RP peak, due to the appearance of new dislocations promoted by the plastic deformation, takes place. As it can be seen from the Figure the NP at $800 \mathrm{~K}$ is absent in the deformed sample, so a relation to the dislocation structure can be ruled out.

The decrease in the LTP height for the deformed sample can be explained taking in consideration that the plastic deformation generates new out of equilibrium dislocations near the grain boundaries which decrease the grain boundary mobility ${ }^{6,14}$. During a subsequent warming run (empty circles) the background decreases, the LTP increases and 
the RP decreases due to the annealing during the previous heating run, as it could be expected.

To show more clearly the movement of the height of NP during the successive thermal cycles, the subtraction of background damping by means of Peak Fit V. $4{ }^{19}$ using cubic polynomials was done firstly and subsequently the net spectra were deconvoluted by means of Peak Fit using the secondderivative method with Gaussian functions, see Figure 2. For as-received samples, good and stable deconvoluted spectra were obtained with four peaks (LTP, RP, ITP and NP) within the temperature interval between room temperature and 973 $\mathrm{K}$. In contrast, for samples annealed during the thermal cycles, the deconvoluted spectra involved only three peaks (LTP, ITP and NP), within the temperature interval from room temperature to $973 \mathrm{~K}$. Even if the deconvolution solution is not unique, the deconvoluted peaks were within a discrepancy bandwidth less than 5\%. This value involves also the discrepancy due to the background subtractions.

Figure 3 shows the behaviour of the ratio between the value of the shear elastic modulus as a function of temperature, $\mathrm{G}(\mathrm{T})$, and the value of the elastic modulus measured at room temperature, G(RT), for the spectra shown in Figures 1. The copper substrate exhibits a fall at around $500 \mathrm{~K}$ related to the development of LTP and an inverse step at around 620 $\mathrm{K}$ which can be related to RP (full green circles). The small inverse modulus jump as a function of temperature at around $650 \mathrm{~K}$, which is near to the half of the homologue temperature, could be related to the recrystallization process. However, the difference between recovery and recrystallisation is sometimes difficult to define, because recovery plays an important role in nucleating recrystallization. Therefore, in some cases the two phenomena cannot be clearly distinguished ${ }^{20-22}$. Nevertheless, recovery and recrystallisation are generally considered as two different phenomena. For instance, for isothermal annealing, the rate of recovery decreases as the annealing time increases. On contrary, the recrystallisation process is rather different, because it develops through nucleation and growth processes ${ }^{20-23}$. Moreover, the appearance of a

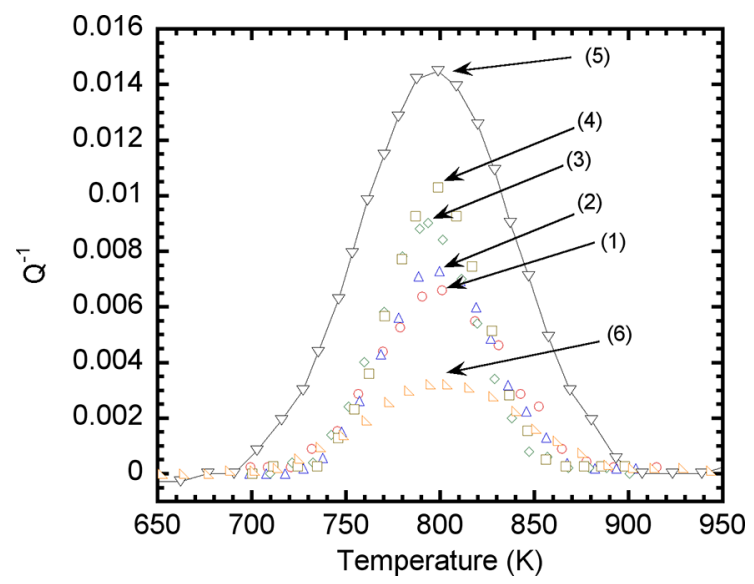

Figure 2. Deconvoluted NP during warming for six thermal cycles, labelled as above. Broken lines are a guide for the eyes.

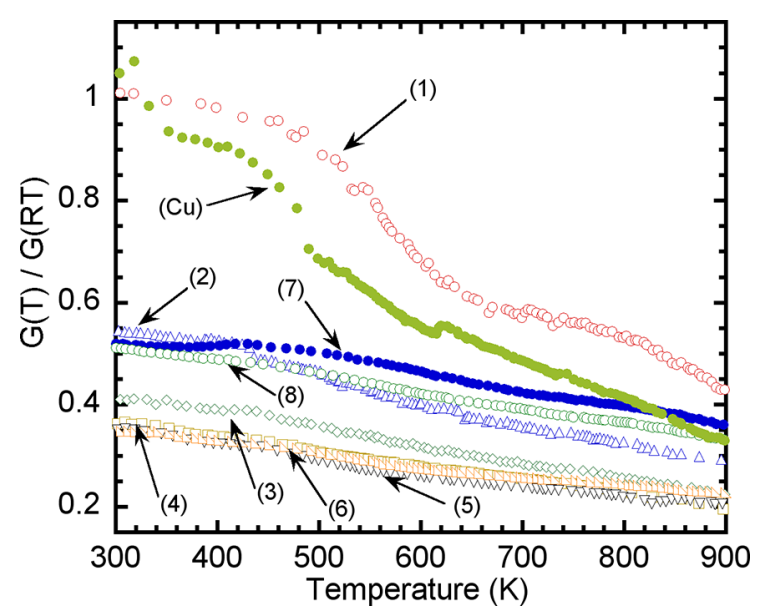

Figure 3. Ratio between the shear elastic modulus as a function of temperature, $\mathrm{G}(\mathrm{T})$, and the value of the elastic modulus measured at room temperature, $\mathrm{G}(\mathrm{RT}) ; \mathrm{G}(\mathrm{T}) / \mathrm{G}(\mathrm{RT})$ for the spectra shown in Figures 1. Labels are used identical to Figure 1. Curves measured during warming.

recovery of the dislocations prior to recrystallization is in agreement with the low stacking fault energy for copper ${ }^{20,21}$.

In contrast, for electrodeposited samples, there appear two drops in the modulus curve for the first warming run at around $500 \mathrm{~K}$ and $800 \mathrm{~K}$, which are related to the appearance of LTP and NP, respectively (see empty circles).

The modulus curves during the cooling part of the thermal cycles appear almost overlap to the modulus ones in the next warming run. For the sake of clarity, the cooling curves are not shown in the Figure. It is interesting to note that the strong steps in the modulus which appear at around $500 \mathrm{~K}$ and $800 \mathrm{~K}$, for the first warming, almost vanish during the successive thermal cycles, i.e. the moduli curves exhibit a soft linear decrease as the temperature increases.

The successive decrease in the modulus curves, mainly among cycles \#1 and \#3, together with the decrease in the height of the LTP, point to a possible dissolution process of precipitates or agglomerate of defects.

In fact, Schoeck had demonstrated that the appearance of incoherent or semi-coherent precipitates leads to the development of a damping peak. In contrast, coherent precipitates cannot produce a damping peak, only promoting a change in the background values ${ }^{24,25}$. So, from a straightforward analysis, the modification of the ellipsoid of stresses into the matrix due to the dissolution of precipitates (or agglomerates) could lead to the appearance of a damping peak.

The dependence of NP on the oscillating frequency was also investigated. The oscillating frequency was changed in around one order of magnitude from 0.2 to $4 \mathrm{~Hz}$. The activation energy calculated from an Arrhenius plot ${ }^{6,15}$ for the LTP in the copper sample was $154 \mathrm{~kJ} / \mathrm{mol}$, which is close to the self diffusion value for copper. Moreover, the activation energy values calculated for the LTP peaks during the different thermal cycles for electrodeposited sample were 
similar to the copper. Nevertheless, for NP an activation energy around $800 \mathrm{~kJ} / \mathrm{mol}$ was obtained, then, it could be proposed that NP does not move with the shift in frequency and consequently it is not a thermally activated peak. The small shift in frequency of NP can be controlled by the uncertainties from the deconvolution plus the background subtraction processes.

Figure 4 shows the behaviour of $\mathrm{S}$ parameter as a function of temperature for some heating runs of the whole group of measurements shown in Figure 1. As it can be seen from the Figure, the substrate exhibits during the first warming, small values of $\mathrm{S}$ with a monotonous increase as the temperature increases. In contrast, the electrodeposited sample exhibits a peak in $\mathrm{S}$ with a maximum at around $600 \mathrm{~K}$. In fact, $\mathrm{S}$ increases up to a temperature near the recovery and then it decreases up to the temperature of NP $(800 \mathrm{~K})$, where $\mathrm{S}$ values became almost null. The appearance of ADD can be controlled by the thermally assisted break-away of the dislocations from weak pinning points, i.e. small precipitates or agglomerate of defects $\mathrm{S}^{6,26,27}$. The increase in $\mathrm{S}$ up to around $600 \mathrm{~K}$ can be easily explained taking into consideration that the mobility of dislocations is increased due to the development of the recovery process, in agreement with the above mentioned results. As the temperature increases, the mobility of dislocations increases and then the $\mathrm{S}$ values should increase too. Nevertheless, the $\mathrm{S}$ values decrease for temperatures higher than $600 \mathrm{~K}$. This effect can be controlled by the dissolution of interacting obstacles with the dislocation in movement which result in agreement with the assumption of the dissolution of precipitates or agglomerate of defects. In addition, during the cooling, the behaviour of S curves is reversible, describing the same kind of curve. In contrast, the behaviour of $\mathrm{S}$ values for a heating run after an annealing up to $1173 \mathrm{~K}$, where the NP does not appear, is more alike the copper due to most of the precipitates or agglomerate of defects have been dissolved.

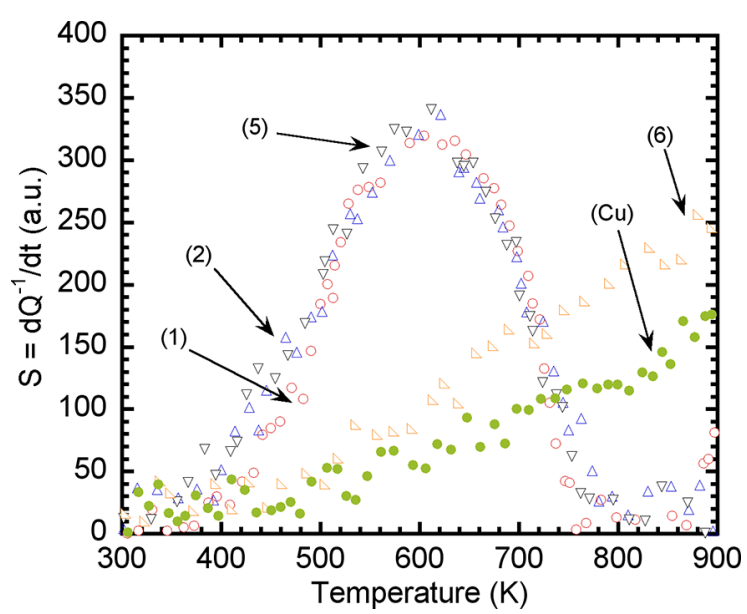

Figure 4. $\mathrm{S}=\Delta Q^{-1} / \Delta \varepsilon_{0}$ as a function of temperature for the substrate and some thermal cycles performed on electrodeposited sample. Labels are used identical to previous figures.
In order to check the appearance of a dissolution process during the warming and re-precipitation or re-agglomeration of defects during cooling, $\mathrm{c}$ were performed in an electrodeposited sample during two thermal cycles up to $1023 \mathrm{~K}$. Figure 5 shows the thermograms after the base-line subtraction for two consecutive heating runs in electrodeposited sample. A clear endothermic reaction is resolved during the first heating which develops as exothermic reaction during the cooling (not shown in the Figure for reasons of clarity). This kind of behaviour is usual for the dissolution of precipitates or agglomerates of defects, during the heating run. Indeed, the iron-aluminium electrodeposit was determined to exhibit a composition around $\mathrm{Fe} 2.5 \mathrm{wt} \% \mathrm{Al}^{5}$, so the dissolution mechanism should be related to agglomerates of defects; in agreement with the iron-aluminium phase diagram ${ }^{28}$. During the second heating run, the intensity of the endothermic reaction decreases in agreement with the above discussion.

Figures 6.a and 6.b show photographs of $\mathrm{Fe}-\mathrm{Al}$ deposit for a sample prior and after eight thermal cycles shown in Figure 1. For both samples in all their surfaces the same characteristic is exhibited. The morphology of the copper substrate and the electrodeposits, for different deposition potential have been already studied by SEM and reported in Ref. ${ }^{5}$. As it can be seen from Figures 6, the morphology of the electrodeposited surface is very similar either; before and after the annealing treatments performed during the mechanical spectroscopy tests. It indicates that both: (i) the dissolution process is not related to a morphologic change at the electro-deposit during the thermal cycles, in agreement with the Fe-Al phase diagram ${ }^{28}$ for the composition of the electrodeposit $(\mathrm{Fe} 2.5 \mathrm{wt} \% \mathrm{Al})$. (ii) changes in the morphology of the deposit have not occurred, e.g. denuded zones, cracks, etc. So, the behaviour shown in the mechanical spectroscopy response corresponds to a microstructural evolution which takes place upon thermal treatments.

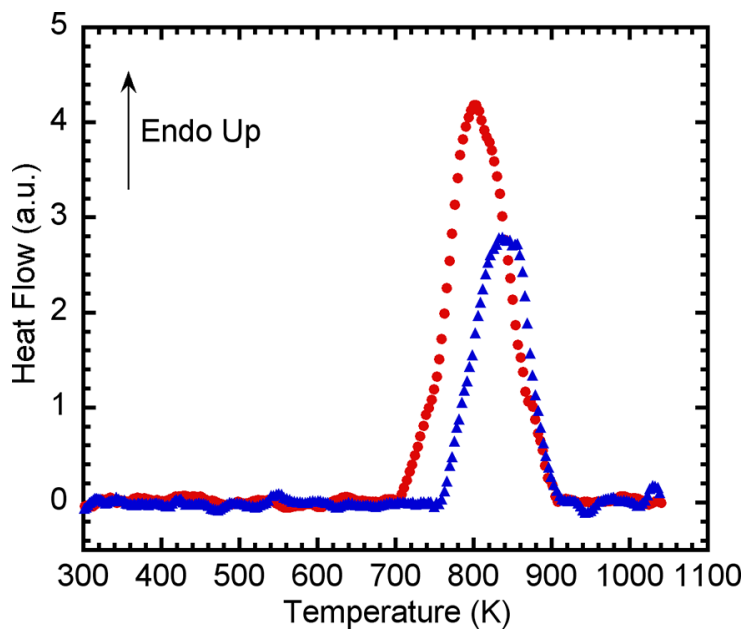

Figure 5. DTA thermograms measured during heating runs for an electrodeposited sample. Circles: first heating run. Triangles: second heating run. 


\section{A}

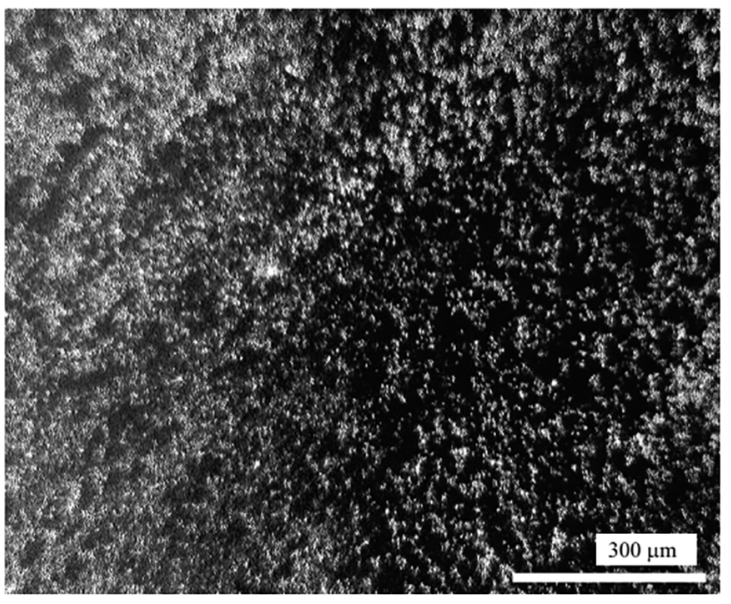

B

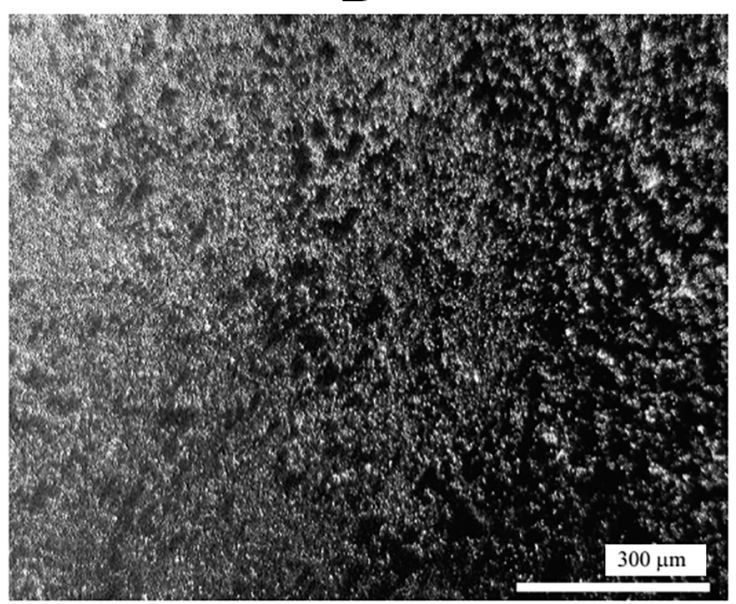

Figure 6. Photography of the electrodeposited sample prior (a) and after (b) the eight thermal cycles shown in Figure 1 taken with green laser light.

\section{Conclusion}

Electrodeposited samples exhibit a new damping peak whose peak temperature is around $800 \mathrm{~K}$. The peak is not thermally activated, i.e. the peak temperature does not shift as the frequency is modified. The physical mechanism controlling the appearance of this new peak is the dissolution and reagglomeration of small agglomerates of defects which take place at around $800 \mathrm{~K}$, during heating and cooling, respectively. This process could occur either in the copper substrate or at the $\mathrm{Fe}-\mathrm{Al}$ electrodeposit. More effort is necessary to be done in order to resolve the kind of precipitates or agglomerates and the matrix where they are taking place.

\section{Acknowledgements}

This work was supported by the CONICET-PIP [179CO], PIDUNR [ING 450], [ING 453], 2014-2017; Collaboration Agreement between the Clausthal University of Technology and the Universidad Nacional de Rosario [CS 2292/2015], 2015 - 2020. Funding by DFG, EN 370/27-1 is also gratefully acknowledged

\section{References}

1. Cullity BD. Introduction to Magnetic Materials. Reading: Addison-Wesley; 1972.

2. Bozorth RM. Ferromagnetism. New York: Van Nostrand; 1951.

3. Lambri OA, Pérez-Landazábal JI, Cano JA, Recarte V. Mechanical spectroscopy in commercial Fe-6 wt.\% Si alloys between 400 and 1000 K. Materials Science and Engineering: A. 2004;370(1-2):459-463.

4. Lambri OA, Pérez-Landazábal JI, Cuello GJ, Cano JA, Recarte $\mathrm{V}$, Siemers C, et al. Mechanical spectroscopy in Fe-Al-Si alloys at elevated temperatures. Journal of Alloys and Compounds. 2009;468(1-2):96-102.

5. Giridhar P, Weidenfeller B, El Abedin SZ, Endres F. Electrodeposition of iron and iron-aluminium alloys in an ionic liquid and their magnetic properties. Physical Chemistry Chemical Physics. 2014;16(20):9317-9326.

6. Schaller R, Fantozzi G, Gremaud G, eds. Mechanical Spectroscopy 2001. Zurich: Trans Tech; 2001.

7. Lambri OA. A Review on the Problem of Measuring Nonlinear Damping and the Obtainment of Intrinsic Damping. In: Martinez-Mardones J, Walgraef D, Wörner CH, eds. Materials Instabilities. Singapore: World Scientific Publishing; 2000. p. 249-280.

8. Lazan BJ. Damping of Materials and Members in Structural Mechanics. Oxford: Pergamon Press; 1968.

9. Zelada-Lambri GI, Lambri OA, García JA. Mechanical energy losses due to the movement of dislocations in molybdenum at high temperatures $(0.3 \mathrm{Tm})$. Journal of Nuclear Materials. 2006;353(1-2):127-134.

10. Molinas BJ, Lambri O, Weller M. Study of non-linear effects related to the Snoek-Köster relaxation in $\mathrm{Nb}$. Journal of Alloys and Compounds. 1994;211-212:181-184.

11. Kehl GL. Fundamentos de la Práctica Metalográfica. Madrid: Aguilar; 1954.

12. Lambri OA, Peñaloza AV, Morón-Alcain AV, Ortiz M, Lucca FC. Mechanical dynamical spectroscopy in $\mathrm{Cu}-\mathrm{Li}$ alloys produced by electrodeposition. Materials Science and Engineering: A. 1996;212(1):108-118 
13. Lambri OA, Lambri GI, Torio ME, Celauro CA. Mechanical dynamical spectroscopy in low-flux neutron irradiated pure copper. Journal of Physics: Condensed Matter. 1996;8:1025310261.

14. Povolo F, Molinas BJ. Present state of the controversy about the grain boundary relaxation. Il Nuovo Cimento D. 1992;14(3):287332 .

15. Nowick AS, Berry BS, eds. Anelastic Relaxation in Crystalline Solids. New York: Academic Press; 1972.

16. Mosher DR, Raj R. Use of the internal friction technique to measure rates of grain boundary sliding. Acta Metallurgica. 1974;22(12):1469-1474.

17. Lambri OA, Riehemann W, Trojanová Z. Mechanical spectroscopy of commercial AZ91 magnesium alloy. Scripta Materialia. 2001;45(12):1365-1371.

18. Lambri OA, Riehemann W, Salvatierra LM, García JA. Effects of precipitation processes on damping and elastic modulus of WE 43 magnesium alloy. Materials Science and Engineering: A. 2004;373(1-2):146-157.

19. PeakFit. V. 4. Erkrath: Jandel Scientific Software; 1995.
20. Lambri OA, Riehemann W. Recovery and recrystallisation processes in plastically deformed WE43 alloy. International Journal of Materials Research. 2011;102(12):1438-1445.

21. Humphreys FJ, Hatherly M. Recrystallisation and Related Annealing Phenomena. Oxford: Pergamon; 2002.

22. Gottstein G, Shvindlerman LS. Grain Boundary Migration in Metals: Thermodynamics, Kinetics, Applications. Boca Raton: CRC Press; 1999.

23. Cahn RW, Haasen P, eds. Physical Metallurgy. Amsterdam: North-Holland; 1983.

24. Lambri OA, Riehemann W. Damping due to incoherent precipitates in commercial QE22 magnesium alloy. Scripta Materialia. 2005;52(2):93-97.

25. Schoeck G. Internal Friction Due to Precipitation. Physica Status Solidi (b). 1969;32(2):651-658.

26. Granato AV, Lücke K. Theory of Mechanical Damping Due to Dislocations. Journal of Applied Physics. 1956;27(6):583-593.

27. Friedel J. Dislocations. Reading: Addison-Wesley; 1967.

28. Massalski TB, Okamoto H, Subramanian PR, Kacprzak L, eds. Binary Alloy Phase Diagrams. 2nd ed. Materials Park: ASM International; 1990. 